\title{
ICT INNOVATION: FROM CONTROL TO RISK AND RESPONSIBILITY
}

Piero Bassetti ${ }^{1}$, Claudio Ciborra ${ }^{2}$, Edoardo Jacucci ${ }^{3}$, and Jannis Kallinikos ${ }^{4}$

${ }^{I}$ President Bassetti Foundation on Innovation and Responsibility, Milan, Italy; ${ }^{2}$ Professor of Information Systems, LSE, UK; ${ }^{3}$ Doctoral Student, Oslo University, Norway; ${ }^{4}$ Reader of Information Systems, LSE, UK

The deployment of innovation in ICT, as in other major technologies, has been governed by models and procedures of risk management and control aimed at eliciting the main risks factors of innovation processes and the planning for appropriate control interventions. For example, software engineering has come up with rigorous methods for software projects risks management. But also the management of information systems has developed methods to identify, quantify and control major and minor risks that punctuate the design and implementation of information systems in organizations. What is common to most of these approaches is the quantitative notion of risk linked to the expected value of a possible danger affecting the project. And a series of assumptions concerning: the closed boundaries of the project, the system, the application; and the unified point of decision making responsible for risk management.

The Panel wants to challenge this widely accepted framework and report from a recent research project on the dual nature of risk. Also, it wants to introduce into the debate a large body of the social science literature on risk (Beck; Luhmann; Douglas; Giddens) that has been systematically ignored by the software engineering, IS and strategy scholars in their studies on risk and ICT.

The following areas will be for discussion:

- The multiple, non linear, and reflexive relationships between risk and ICT

- The dynamics of side-effects in ICT infrastructures 
- The problematic aspects of the notion of responsibility when risks cannot be fully calculated and governed (and the ensuing impacts on the deployment of innovations)

- The unexpected effects of representing risk as a calculable entity in the management of projects

- The decline of boundary drawing and boundary management (e.g. loose coupling) as forms of containing and managing risks in a connected world.

The broad themes addressed by the panelists regard Control, Knowledge, Responsibility and Life.

\section{CONTROL}

The ways by which ICT currently develops (large scale systems, infrastructures, the internet) violates some crucial premises upon which control has traditionally been predicated. An appreciation of the issues that are at stake makes, however, necessary the historical understanding of the traditional forms by which technology has been involved in the regulation of human affairs. Despite significant variations brought about the diffusion of IT-based artefacts, traditional forms of technological control remain operative and are clearly reflected in the way technical artefacts are designed, implemented and managed. Furthermore, the appreciation of the current developments presupposes the adequate understanding of the older system of technological control and the fractures, which grid technologies and the internet afflict upon it. Traditional forms of technological control could be understood in terms of functional simplification and closure (Luhmann). Functional simplification involves the demarcation of an operational domain within which the complexity of the world is reconstructed as a simplified set of causal/instrumental relations or, as in the case of ICT, as a simplified set of procedures. Functional closure implies the construction of a protective cocoon that is placed around the selected causal sequences to safeguard their recurrent unfolding. While possible to gauge in similar terms, the involvement of large-scale information systems in organizations spin a web of technological relations throughout the organization in ways that reconfigures the boundaries of the technological and social domains and blurs the distinctions between referential reality and representation. The traditional forms of technological control, predicated upon the premises of functional simplification and closure, are thereby challenged. These trends are further accentuated by the diffusion of the internet and other grid technologies, and the exit of technology from the secluded world of organizations into the open realm of everyday life. 


\section{KNOWLEDGE}

Knowledge and risk are closely related at a conceptual level. They are opposites. Risk is what we are confronted with when we do not know what will happen. And in the theory of High Reliability Organization learning from experience in general and from failures in particular is one of the key strategies to avoid accidents and disasters. But there are important barriers and limits to learning which cannot be overcome, and which imply that there are serious limits to the degree we can reduce risks stemming from complex technologies by means of knowledge and learning. Some of these are extrinsic to the knowledge and learning processes, like organizational politics and group interests. Others are intrinsic to knowledge and learning. These limits relate to the partiality of all knowledge, the complexity of the systems of knowledge we are applying related to complex technologies. This implies that there are always unanticipated side-effects of applying any (new) knowledge, conflicting and incompatible systems of knowledge, that a complex system of knowledge gets a character of an independent, autonomous actor. A case study on electronic patient records will exemplify this theme.

\section{RESPONSIBILITY}

It is usually understood that ICT as many other innovations can create benefits for organizations operating on markets. What gets overlooked however is that ICT may have an impact on political institutions and hence on the expression of political power. If ICT innovation means "change", if it creates new opportunities as well as risks in the society, who is responsible? In particular who is accountable for the assessment of the social risks of ICT? Often, the political and social institutions do not know how, or are in general unwilling to pick up the responsibilities connected to ICT innovations. It is high time that they consider such a possibility.

\section{LIFE}

Finally, the economic and sociological analyses of ICT and risk need to be complemented by a phenomenological/existential one. Life, risk and technology are getting more intimate. The extension of the domain of quantifiable knowledge and representation exposes us to the danger of the further growth of ignorance generated by the new interdependencies and side-effects created by grid technologies. The essence of such a reflexive 
process needs to be captured by a new notion of risk combined with a new perspective on the question of technology.

The challenge emerging when looking at the next developments in ICT platforms and in risk management is that the unfolding of our life (projects) is conditioned, constrained and enabled by grid technologies. Technology is already there, albeit in an indirect and hidden form when we apply for a loan or seek a life insurance scheme. Next, it will be there in helping us compute whether we should engage in a house move or a career change; whether we can afford a certain course of studies rather than another. For each life choice grid technologies will be able to offer a calculus of probabilities and thus quantify our life projects. Only an exploration of life, risk and technology can offer us some clues to grasp these future developments. 